\title{
INDICADORES BIOFÍSICOS E A SUSCETIBILIDADE A SECAS DO ALTO VALE DA SUB-BACIA DO RIO PIRACURUCA (CE-PI)
}

\author{
Francílio de Amorim dos Santos* \\ Instituto Federal do Piauí
}

\author{
Maria Lúcia Brito da Cruz** \\ Universidade Estadual do Ceará
}

Resumo: O Nordeste do Brasil (NEB) exibe condições ambientais bastante peculiares, demandando estudos integrados para subsidiar o conhecimento da suscetibilidade da área à ocorrência de secas. 0 objetivo da pesquisa foi avaliar a suscetibilidade biofísica do Alto Curso da Sub-bacia Hidrográfica do rio Piracuruca, considerando a integração de dados de declividade média do relevo, do índice de aridez, da temperatura à superfície do solo e do índice de vegetação ajustado ao solo, como subsídio ao estudo das secas. A pesquisa empregou álgebra de mapas para integração de variáveis biofísicas - declividade média do relevo, índice de aridez, temperatura à superfície do solo e índice de vegetação ajustado ao solo - para estimativa da suscetibilidade biofísica do Alto Vale. A área estudada situa-se sobre a formação Serra Grande, que é formada, principalmente, por arenitos, com relevo apresentando marcas do processo de dissecação oriundo da rede de drenagem consequente. A área está sob a influência da Zona de Convergência Intertropical (ZCIT), que atual em associação com o El niño Oscilação Sul (ENOS) e o dipolo do Atlântico. Foram identificadas as seguintes ordens de solos: os Gleissolos, os Latossolos, os Neossolos e os Planossolos. Esses solos são recobertos por mata plúvio-nebular, no topo do Planalto, e caatinga arbustiva a arbórea, nas bordas do Planalto e áreas mais rebaixadas. As variáveis indicaram predominância de: relevo plano em $69,4 \%$ da área; alta e muito alta aridez em $51,8 \%$ do Alto Vale; temperatura à superfície do solo entre 30,1 a $36,0^{\circ} \mathrm{C}$ em $80,2 \%$ da área pesquisada; vegetação com baixa atividade fotossintética em $62,0 \%$ do setor em estudado.

Palavras-chave: Bacia Hidrográfica. Norte do Nordeste do Brasil. Desastre natural. Suscetibilidade biofísica.

\section{BIOPHYSICAL INDICATORS AND THE DROUGHT SUSTAINABILITY OF THE HIGH VALLEY OF THE RIO PIRACURUCA SUBBASIN (CE-PI)}

Abstract: Northeast Brazil (NEB) exhibits very peculiar environmental conditions, requiring integrated studies to support the knowledge of the area's susceptibility to the occurrence of droughts. The objective of the research was to evaluate the biophysical susceptibility of the High Course of the Hydrographic Sub-basin of the Piracuruca River, considering the integration of data of the average relief slope, the aridity index, the temperature at the soil surface and the vegetation index adjusted to the soil, as a subsidy to the study of droughts. The research used map algebra to integrate biophysical variables - average slope of the relief, aridity index, temperature at the soil surface and vegetation index adjusted to the soil - to estimate the biophysical susceptibility of Alto Vale. The studied area is located on the Serra Grande formation, which is formed mainly by sandstones, with relief showing marks of the dissection process from the consequent drainage network. The area is under the influence of the Intertropical Convergence Zone (ZCIT), which currently exists in association with the El Niño Oscilação Sul (ENOS) and the Atlantic dipole. The following soil orders were identified: Gleisols, Oxisols, Neossols and Planossols. These soils are covered by nebulous rainforest, at the top of the Plateau, and shrubby to arboreal caatinga, at the edges of the Plateau and lower areas. The variables indicated a predominance of: flat relief in $69.4 \%$ of the area; high and very high aridity in $51.8 \%$ of Alto Vale; soil surface temperature between 30.1 to $36.0^{\circ} \mathrm{C}$ in $80.2 \%$ of the surveyed area; vegetation with low photosynthetic activity in $62.0 \%$ of the sector under study.

Keywords: Hydrographic basin. North of Northeast Brazil. Natural disaster. Biophysical susceptibility.

\section{INDICADORES BIOFÍSICOS Y LA SOSTENIBILIDAD SECOSA DEL ALTO VALLE DE LA SUBCUENCA DEL RÍO PIRACURUCA (CE-PI)}

Resumen: El noreste de Brasil (NEB) exhibe condiciones ambientales muy peculiares, que requieren estudios integrados para respaldar el conocimiento de la susceptibilidad del área a la ocurrencia de sequías. El objetivo de la investigación fue evaluar la susceptibilidad biofísica del curso alto de la subcuenca hidrográfica del río Piracuruca, considerando la integración de datos de la pendiente de alivio promedio, el índice de aridez, la temperatura en la superficie del suelo y el índice de vegetación ajustado al suelo, como subsidio al estudio de las sequías. La investigación utilizó álgebra de mapas para integrar variables biofísicas (pendiente promedio del relieve, índice de aridez, temperatura en la superficie del suelo e índice de vegetación ajustado al suelo) para estimar la susceptibilidad biofísica de Alto Vale. El área estudiada se encuentra en la formación Serra Grande, que está formada principalmente por areniscas, con relieve que muestra marcas del proceso de disección de la red de drenaje consecuente. El área está bajo la influencia de la Zona de Convergencia Intertropical (ZCIT), que actualmente existe en asociación con El Niño Oscilação Sul (ENOS) y el dipolo del Atlántico. Se identificaron las siguientes órdenes de suelo: Gleisoles, Latosoles, Neosoles y Planosoles. Estos suelos están cubiertos por una nebulosa selva tropical, en la parte superior de la meseta, y arbustiva a caatinga arbórea, en los bordes de la meseta y las zonas más bajas. Las variables indicaron un predominio de: relieve plano en $69.4 \%$ del área; aridez alta y muy alta en $51.8 \%$ de Alto Vale; temperatura de la superficie del suelo entre 30.1 a $36.0^{\circ} \mathrm{C}$ en el $80.2 \%$ del área estudiada; vegetación con baja actividad fotosintética en $62.0 \%$ del sector en estudio.

Palabras clave: Cuenca hidrográfica. Norte del noreste de Brasil. Desastre natural. Susceptibilidad biofísica. 
Introdução

0 Nordeste brasileiro apresenta condições ambientais bastante peculiares, com destaque para a região semiárida, área onde se localiza o recorte espacial elencado para realização da pesquisa. Dentre outras características, o semiárido nordestino é marcado pela presença de relevo em processo de aplainamento, rios intermitentes, distinto mosaico de solos e de fisionomias da cobertura vegetal, além de condições climáticas cujas anomalias pluviométricas têm gerado desastres naturais, a exemplo das secas.

Nesse sentindo, tornou-se de grande relevância empreender estudo voltado ao conhecimento dos principais elementos que compõem a paisagem local, de forma integrada, como possiblidade para construção de um banco de dados e, como tal, subsidiar o conhecimento da suscetibilidade da área à ocorrência de secas. Reiterase, também, a importância de estudos integrados para identificação das potencialidades ligadas ao uso das terras e, também, indicação de áreas com limitações à ocupação e ao uso dos componentes da paisagem.

Os desastres naturais dizem respeito à manifestação de eventos naturais em áreas habitadas, com potencial para causar impactos diversos a depender de sua intensidade, duração e contingente populacional atingido. Dessa forma, cabe expressar que os desastres naturais são compreendidos como uma situação que ao ocorrer supera a capacidade de suporte local, fato que demanda ajuda a nível nacional ou internacional para superação, tendo em vista os grandes danos, destruição e sofrimento humano oriundos da manifestação do evento natural (CRED/EM-DAT, 2016).

Nesse estudo, a tipologia de desastre natural abordada foram as secas, classificadas como desastre de natureza climática. De acordo com Ayoade (2001), as secas podem ser: permanente, ocorrendo quando os totais pluviométricos são insuficientes para atender a demanda hídrica das plantas; sazonal, com periodicidade ao longo dos anos; contingente, que ocorre quando a chuva deixa de precipitar por um dado período de tempo; e invisível, fruto de um desequilíbrio entre a quantidade de água disponível no solo ou das precipitações e as necessidades hídricas das plantas.

De acordo com Ramos (2010), os tipos de secas descritas, acima, ocorrem de forma sucessiva à medida que a seca evolui, pois a redução nos valores de precipitação (seca meteorológica) gera redução na umidade do solo e, como tal, afeta as culturas agrícolas (seca agrícola) e diminui o escoamento e o armazenamento de água (seca hidrológica). 0 autor complementa, ainda, que permanecendo essas condições de diminuição/ausência de precipitação as principais atividades baseadas no uso da água podem ser afetadas e, desse modo, tendo a seca socioeconômica, foco da pesquisa.

Nesse cenário, cabe salientar a importância dos estudos sobre desastres naturais de forma integrada, onde se possa conhecer a dinâmica dos componentes da paisagem. Nesse sentido, elegeu-se a bacia hidrográfica como recorte espacial para estudo, que Suertegaray (2009) aponta como uma unidade espacial que possibilita a integração e, conforme atesta Pinheiro (2011), apresenta caráter sistêmico, tendo em vista que constitui um sistema aberto e sujeito a entrada e saída de energia e de matéria.

Desse modo, tomando-se como base a bacia hidrográfica como elemento integrador da paisagem é possível inferir sua suscetibilidade à ocorrência de secas. A suscetibilidade diz respeito ao potencial que determinada área possui a ocorrência de processos naturais e induzidos (BRASIL, 2007). De acordo com Listo (2011), a suscetibilidade está associada a um conjunto de fatores naturais presentes em dada área e que determinam seu potencial para deflagração de determinados desastres.

Nesse sentido, o estudo descrito empregou álgebra de mapas para integração de quatro variáveis biofísicas - declividade média do relevo, índice de aridez, temperatura à superfície do solo e índice de vegetação ajustado ao solo - como possibilidade para conhecimento do ambiente e estimativa da sua suscetibilidade à ocorrência de secas. Destaca-se que os procedimentos para manuseio, refinamento e geração do produto final foi realizado no Sistema de Informação Geográfica (SIG) ArcGIS e no SPRING, ao passo que o layout final do mapas foi executado no QGIS.

Em suma, foi empregado esforço para o conhecimento de algumas características do Alto Curso da Sub-bacia Hidrográfica do rio Piracuruca e, como tal, possibilitar o planejamento e implementação de ações voltadas à melhoria da qualidade ambiental. Dessa forma, o estudo teve como objetivo avaliar a suscetibilidade biofísica do Alto Curso da Sub-bacia Hidrográfica do rio Piracuruca, considerando a integração de dados de declividade média do relevo, do índice de aridez, da temperatura à superfície do solo e do índice de vegetação ajustado ao solo, como subsídio ao estudo das secas.

\section{Materiais e métodos}

A área de estudo

O estudo foi desenvolvido no Alto Vale da Sub-bacia 
Hidrográfica do rio Piracuruca (AVSBHP), que abrange uma área de 2.904,4 km2, correspondendo a 37,7\% da área total da referida Sub-bacia. 0 Alto Vale abrange a área de sete municípios cearenses (Carnaubal, Guaraciaba do
Norte, Ibiapina, São Benedito, Tianguá, Ubajara e Viçosa do Ceará) e cinco municípios piauienses (Cocal, Cocal dos Alves, Domingos Mourão, Piracuruca e São João da Fronteira), conforme está representado na Figura 1.

Figura 1 - Localização do Alto Vale da Sub-bacia do rio Piracuruca, situado na divisa dos estados do Ceará e do Piauí, Nordeste do Brasil.

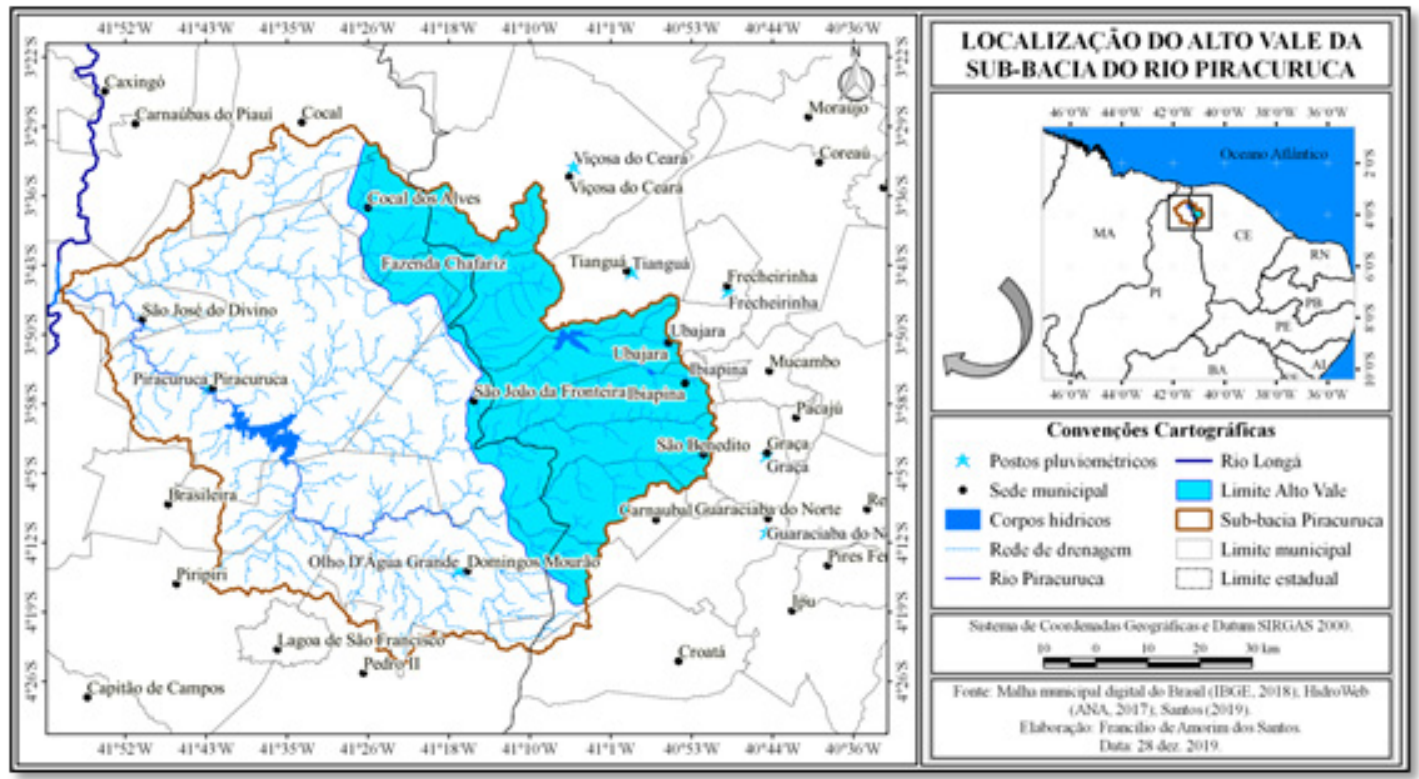

Fonte: Elaborado pelos autores (2020)

Ressalta-se que a área estudada está assentada sobre o Planalto da Ibiapaba, onde se localiza as principais nascentes de seu rio principal, o Piracuruca. Nesse trecho da Sub-bacia do rio Piracuruca situa-se o açude Jaburu I, recurso hídrico de suma importância para o abastecimento e desenvolvimento de atividades humanas, particularmente a fruticultura. 0 referido açude foi construído às margens dos riachos Jaburu e Pitanga, entre os municípios de Ubajara e Tianguá, possuindo capacidade, atual, para armazenar $174.000 .000 \mathrm{~m} 3$.

\section{Procedimento metodológico}

O estudo classifica-se como descritivo, pois sua finalidade está associada à descrição das características de determinada fenômeno ou o estabelecimento das relações entre variáveis (GIL, 2002), que nesse estudo esteve ligado à relação de algumas variáveis ambientais à suscetibilidade biofísica a secas. A pesquisa empregou levantamento bibliográfico e cartográfico, que possibilitou o conhecimento das características ambientais e da suscetibilidade biofísica do Alto Vale da Sub-bacia Hidrográfica do rio Piracuruca.

Reitera-se que foram elencadas quatro variáveis biofísicas para compor o índice de suscetibilidade biofísica a secas (ISBioS). Essas variáveis serão mais bem detalhadas a seguir, bem como os arquivos obtidos e os procedimentos empregados para seu manuseio, refinamento e geração do produto final, que foi reclassificado via SIG ArcGIS, versão 10.2, cuja licença foi obtida pela Universidade Federal do Piauí (UFPI). Foi utilizado, ainda, o SIG SPRING, para manuseio das imagens de satélite. Destaca-se que layout final dos mapas realizado no QGIS, versão 2.14. Ressalta-se que mapeamento final encontra-se escala compatível com 1:100.000.

\section{Declividade média do relevo (Dm)}

Foi relevante conhecer as classes de declividade média do relevo (Dm) da área estudada, tendo em vista que a declividade do relevo tem influência sobre a formação e distribuição dos solos, que, por sua vez, apresentam certas características que possibilitam o maior ou menor acúmulo de água, a exemplo da coesão.

Dessa forma, foi necessária a aquisição de arquivo matricial dos Modelos Digitais de Elevação (MDEs), da Missão Topográfica Radar Shuttle (SRTM) (USGS, 2017a), que possui resolução espacial de 30 metros. Ao passo que, a delimitação dos intervalos para as classes de Dm teve como base o Manual Técnico de Geomorfologia (Tabela 1), do Instituto Brasileiro de Geografia e Estatística (IBGE, 2009). 
Tabela 1 - Intervalos, classes atribuídas e notas de declividade média do relevo (Dm)

\begin{tabular}{ccc}
\hline Intervalos de Dm (\%) & Classes atribuídas & Notas \\
\hline 0 a 3 & Plano & 1 \\
3 a 8 & Suave Ondulado & 2 \\
8 a 20 & Ondulado & 3 \\
20 a 45 & Forte Ondulado & 4 \\
45 a 75 & Montanhoso & 5 \\
\hline
\end{tabular}

Índice de aridez (la)

Salienta-se que esses procedimentos descritos a seguir foram efetuados para obtenção dos dados médios anuais do índice de aridez (la) e das variáveis do balanço hídrico, quais sejam: temperatura, evapotranspiração média anual, número de meses secos, excedente hídrico, déficit hídrico. Desse modo, demandou-se obtenção de dados de precipitação de dez postos pluviométricos (Figura 1), junto ao Sistema de Informações Hidrológicas (HidroWEB), ligado à Agência Nacional de Águas (ANA, 2017), a partir da série histórica de 1985 a 2016. De posse desses dados iniciais foi possível refina-los por meio do emprego de quatro rotinas no pacote de programas USUAIS (Figura 2), conforme sugerem Oliveira e Sales (2016).

Figura 2 - Rotinas executadas no pacote de programas USUAIS.

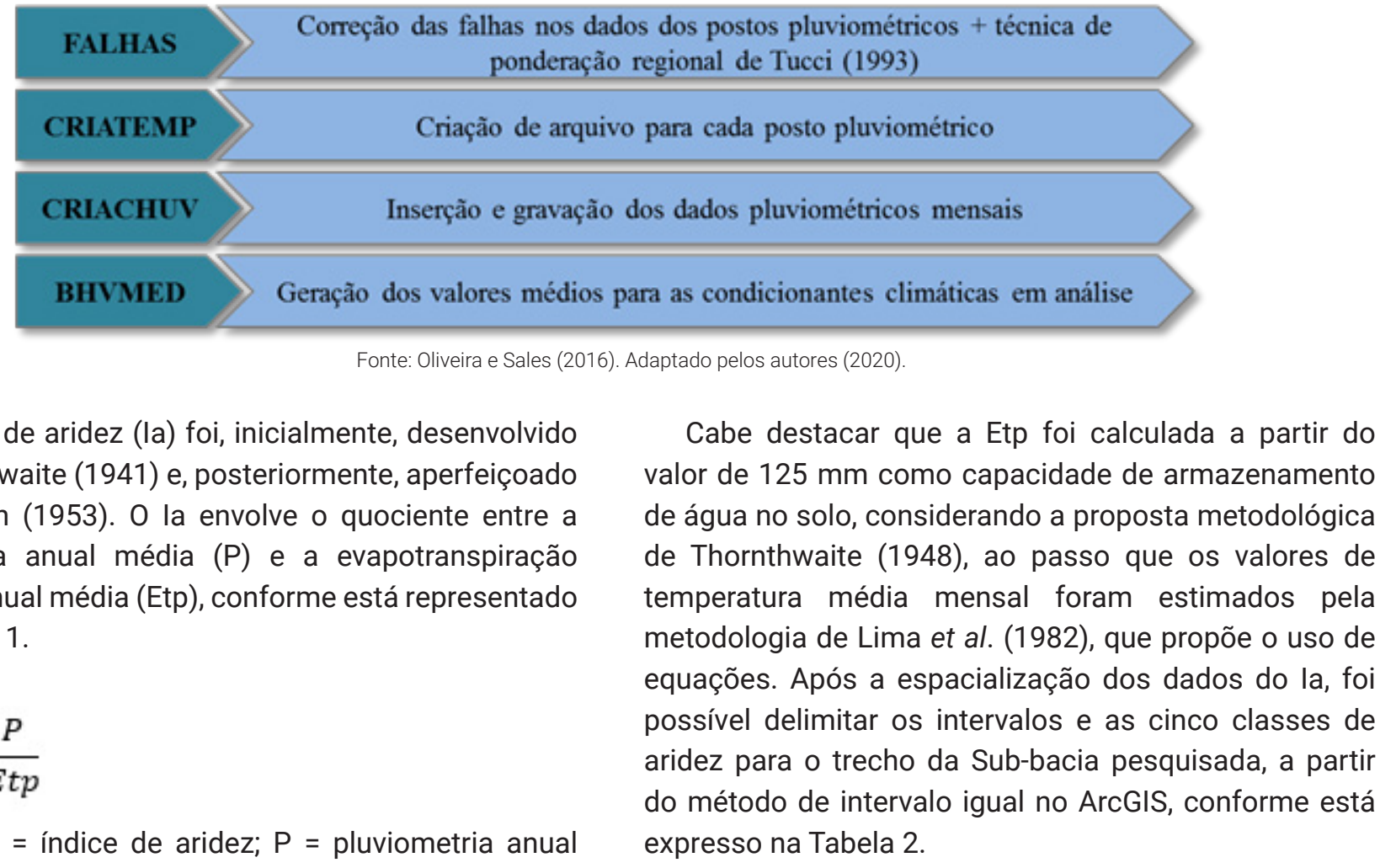

Onde: la = índice de aridez; $\mathrm{P}=$ pluviometria anual média; Etp = evapotranspiração anual média.

Tabela 2 - Intervalos, classes atríbuidas e notas ao índice de aridez (la).

\begin{tabular}{ccc}
\hline Ia & Classes atribuídas & Notas \\
\hline $0,60 \mid--0,86$ & Muito alta & 5 \\
$0,86 \mid--1,12$ & Alta & 4 \\
$1,12 \mid--1,38$ & Média & 3 \\
$1,38 \mid--1,64$ & Baixa & 2 \\
$1,64 \mid--1,90$ & Muito baixa & 1 \\
\hline
\end{tabular}


Para obtenção da temperatura à superfície do solo (Ts) foi necessária a aquisição de imagens do satélite Landsat 8 OLI. Nessas imagens realizou-se o cálculo da radiância monocromática aparente e a emissividade, a partir do sistema imageador Thermal Infrared Sensor (TIRS), que se referem às bandas 10 (Infravermelho Termal/TIRS 1/10.6 - $11.19 \mu \mathrm{m}$ ) e 11 (Infravermelho Termal/TIRS 2/11.5 - $12.51 \mu \mathrm{m}$ ). O software SPRING foi utilizado para conversão dos valores iniciais das imagens em radiância espectral e, posteriormente, para temperatura de brilho (NASA, 2019).

Em seguida, realizou-se a derivação da Fração de Cobertura Vegetal $(F c)$, considerando o SAVI (ZHANG et al., 2012) e, depois, realizado o cálculo dos valores de emissividade da superfície $(\varepsilon)$ a partir do método proposto por Valor e Caselles (1996). Em seguida, foi possível empregar os dados apresentados na Equação 2, para calcular a temperatura à superfície do solo (Ts)
Equação 2

$$
T s=\frac{T b}{1+\left[\lambda * \frac{T b}{\rho}\right] * \ln (\varepsilon)}
$$

Onde: $\lambda=$ Comprimento de onda do brilho emitido;

$$
\rho=h * \frac{c}{\sigma}\left(1.438 * \frac{10^{-2} m}{K}\right)
$$
; $\sigma=$ constante de Boltzmann (1.38*10-23 J/K); h = constante de Planck $\left(6.26 * 10^{-34} \mathrm{~J} / \mathrm{s}\right) ; \mathrm{c}=$ velocidade da luz $\left(2.998 * 10^{8} \mathrm{~m} / \mathrm{s}\right)$.

Realizados os procedimentos, supracitados, foi utilizada a extensão Spatial Analyst Tool e ferramenta Reclassify do ArcGIS, para reclassificação da imagem resultante da aplicação das equações e a partir daí foi executada a delimitação dos intervalos, classes e notas referentes à variável Ts (Tabela 3 ).

Tabela 3 - Intervalos, classes atribuídas e notas da temperatura à superficie do solo (Ts).

\begin{tabular}{ccc}
\hline Intervalos de $\mathrm{Ts}$ & Classes atribuídas & Notas \\
\hline 21,1 a $26^{\circ} \mathrm{C}$ & Muito baixa & 1 \\
26,1 a $30^{\circ} \mathrm{C}$ & Baixa & 2 \\
30,1 a $36^{\circ} \mathrm{C}$ & Média & 3 \\
36,1 a $40^{\circ} \mathrm{C}$ & Alta & 4 \\
\hline
\end{tabular}

Fonte: Santos (2019)

\section{Índice de vegetação ajustado ao solo (SAVI)}

Inicialmente, foi necessária a aquisição de imagens do satélite Landsat $8 \mathrm{OLI}$, com resolução espacial de 30 $\mathrm{m}$, disponíveis no site do United States Geological Service (USGS, 2017b). As referidas imagens apresentam as seguintes características: órbita/ponto 219/62 e 219/63 e data de passagem de 08/08/2016; órbita/ponto 218/63 e data de passagem de 01/08/2016. Destaca-se que as imagens passaram por cálculo da reflectância aparente, correção atmosférica e conversão dos níveis de cinza da imagem (NC) para radiância espectral e, em seguida, para refletância.

Posteriormente, foi aplicada a Equação 3 que se refere ao índice de vegetação ajustado ao solo (SAVI), que considera os efeitos do solo exposto nas imagens, supracitadas, ajustando-se o índice de vegetação da diferença normalizada (NDVI), quando a superfície do solo não está totalmente coberta pela vegetação (BORATTO; GOMIDE, 2013).

Equação 3

$$
S A V I=\frac{(N I R-R)}{(N I R+R+L)} *(1+L)
$$

Onde: $\mathrm{SAVI}=$ índice de vegetação ajustado ao solo; $\mathrm{NIR}$ = fluxo radiante no infravermelho próximo; $\mathrm{R}$ = fluxo radiante na região do vermelho visível; $L$ = fator de ajuste do índice SAVI, nesse estudo assumiu o valor de 0,5, que é aplicado à vegetação com densidade intermediaria.

Em seguida, foram definidos os intervalos e cincos classes para o SAVI, executado por meio da extensão Spatial Analyst Tool e ferramenta Reclassify do ArcGIS, conforme é apresentado na Tabela 4. 
Tabela 4 - Intervalos, classes atribuídas e notas do índice de vegetação ajustado ao solo (SAVI).

\begin{tabular}{ccc}
\hline Intervalos do SAVI & Classes atribuídas & Notas \\
\hline 0,6 a 0,8 & Vegetação com alta atividade fotossintética & 1 \\
0,4 a 0,6 & Vegetação com média atividade fotossintética & 2 \\
0,2 a 0,4 & Vegetação com baixa atividade fotossintética & 3 \\
0,1 a 0,2 & Área urbana / Vegetação com muito baixa atividade & 4 \\
0 a 0,1 & fotossintética & 5 \\
$<0,1$ & Solo exposto & - \\
\hline
\end{tabular}

Índice de suscetibilidade biofísica a secas (ISBioS)

Destaca-se que as informações obtidas em diversas fontes de dados foram de grande relevância para que se pudesse construir o índice de suscetibilidade biofísica a secas (ISBioS) do Alto Vale da Sub-bacia Hidrográfica do rio Piracuruca. Desse modo, foram selecionadas e integradas quatro varáveis biofísicas por meio de álgebra de mapas, conforme está exposto na Equação 4.

Equação 4

$I S$ Bio $_{s}=D m+I a+T s+S A V I$ a secas; $\mathrm{Dm}=$ declividade média do relevo; la = índice de aridez; Ts = temperatura à superfície do solo; SAVI = índice de vegetação ajustado ao solo.

A integração dos dados e geração de produto cartográfico final foi realizada por meio das ferramentas do Sistema de Informação Geográfica (SIG) QGIS, versão 2.14. De posse desse produto, foi possível executar operação para delimitação das cinco classes para o ISBioS, conforme está expresso na Tabelas 5, utilizandose a opção graduado e método quebra naturais (jenks), no QGIS.

Onde: ISBioS = índice de suscetibilidade biofísica

Tabela 5 - Intervalos, classes atribuídas e notas do indice de suscetiblidade biofisica a secas (ISBioS) do Alto Vale da Sub-bacia Hidrográfica do rio Piracuruca

\begin{tabular}{ccc}
\hline Intervalos do ISBios & Classes atribuídas & Notas \\
\hline 4 a 7 & Muito baixa & 1 \\
7 a 9 & Baixa & 2 \\
9 a 11 & Média & 3 \\
11 a 13 & Alta & 4 \\
13 a 17 & Muito alta & 5 \\
\hline
\end{tabular}

Fonte: Elaborado pelos autores (2020)

A partir dos dados adquiridos e procedimentos empregados foi possível conhecer a área do Alto Vale da Sub-bacia do rio Piracuruca e inferir sua suscetibilidade à ocorrência de secas, que periodicamente assolam a população daquela área. Desse modo, a seguir serão apresentados e discutidos os resultados obtidos.

\section{Resultados e discussão}

Como mencionado, acima, o Alto Vale da Sub-bacia do rio Piracuruca está inteiramente situado sobre o Planalto da Ibiapaba, fato que Ihe proporciona características diferenciadas em relação aos demais setores da Subbacia em questão. Características essas que serão mais bem detalhadas a seguir.

Aspectos ambientais gerais

A área estuda situa-se sobre a formação Serra Grande, datada da era Paleozoica e período Siluriano, é formada por rochas de natureza sedimentar, especificamente por arenitos e conglomerados que apresentam intercalações de folhelhos e siltito arenoso; na área do Alto Vale ocorrem falhas que exibem sentido nordeste-sudeste, fruto do lineamento transbrasiliano (CPRM, 2006a; 2006b), que demonstram controle estrutural sobre a rede de drenagem, fazendo com que os rios dessa área apresentem fluxo perpendicular ao do rio Piracuruca, 
principal curso hídrico da Sub-bacia.

0 relevo da área encontra-se bastante dissecado e em processo de aplainamento, exibindo expressivas marcas da influência da rede de drenagem. Destacam-se, ainda, os festonamentos oriundos dos entalhes realizados pelos rios consequentes (Figura 3), na vertente oeste do
Planalto da Ibiapaba rumo ao estado do Piauí, contudo, seu fluxo é perpendicular ao rio principal. Ressalta-se que o referido relevo apresenta extensas áreas planas e exibe cotas altimétricas que variam de 185 a $965 \mathrm{~m}$ (USGS, 2017a).

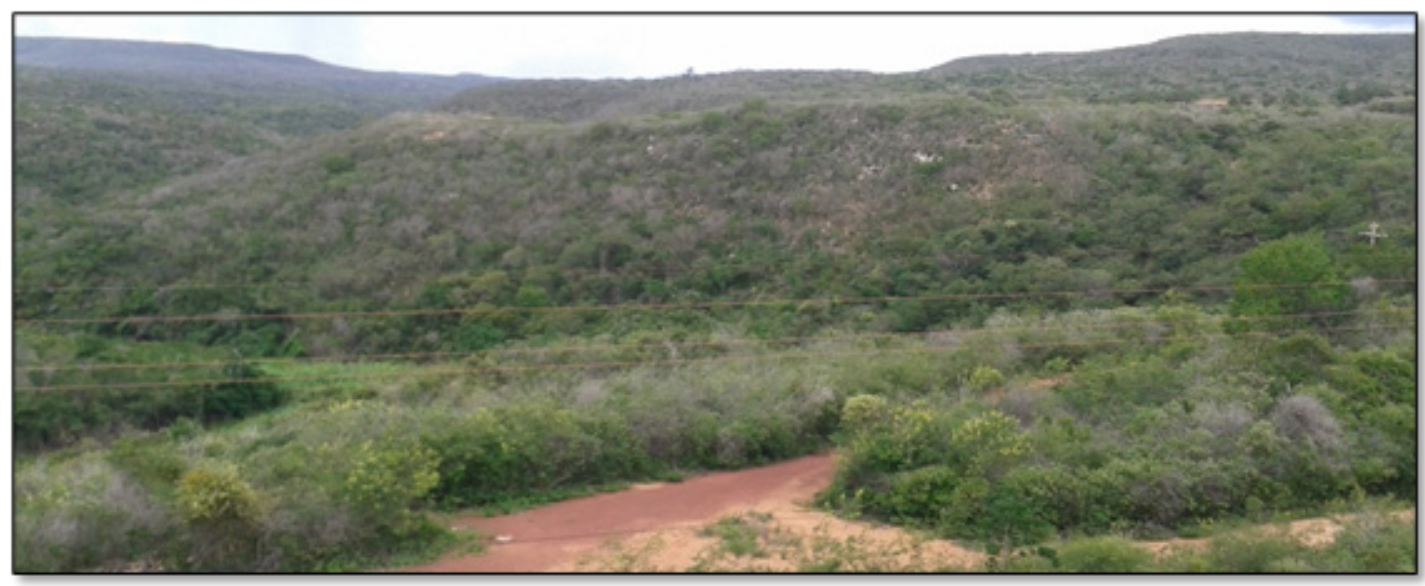

Fonte: Arquivo pessoal (2016)

O Alto Vale da Sub-bacia do rio Piracuruca é influenciado pela Zona de Convergência Intertropical (ZCIT), cujo posicionamento apresenta ligações com os fenômenos oceânicos El niño Oscilação Sul (ENOS) e a diferença da temperatura da superfície das bacias do Atlântico Norte e Atlântico Sul. A associação desses elementos responde pela ocorrência de anos normais ou anômalos, no setor norte do Nordeste do Brasil, em especial na área estudada.

Na Figura 4 pode-se observar a espacialização da média anual de precipitação, temperatura e evapotranspiração potencial do Alto Vale da Subbacia do rio Piracuruca, para os anos de 1985 a 2016. Constata-se o predomínio de: totais pluviométricos situados entre 1.227 a $1.387 \mathrm{~mm}$, que ocorrem em $62,1 \%$ $(1.803,7 \mathrm{~km} 2)$ da área; temperaturas oscilando entre 22,2 a $24,2^{\circ} \mathrm{C}$, frequentes em $61,7 \%(1.792,0 \mathrm{~km} 2)$ da área total estudada; evapotranspiração situada entre 1.102 a 1.302 , que totaliza $62,3 \%(1.809,5 \mathrm{~km} 2)$ da água perdida na área pesquisada.

Reafirma-se a relevância do planalto da Ibiapaba como influenciador das condições de umidade. Nesse sentindo, destacam-se os municípios de Ibiapina e
Ubajara, cujas sedes situam-se no topo do Planalto, que apresentam os maiores volumes pluviométricos, as menores temperaturas e menor perda de água por evapotranspiração potencial. Por outro lado, no sentido leste para oeste em direção ao estado do Piauí os valores dessas variáveis se invertem.

Em suma, ressalta-se que com o distanciamento do Planalto da Ibiapaba acentuam-se as condições de seca, pois se reduzem as precipitações, eleva-se a temperatura e a perda de água por evapotranspiração potencial. Nesse sentido, Rêgo et al. (2018) destaca que a seca, também, está ligada à distribuição da água, limitando a disponibilidade desse recurso à população nordestina, particularmente a rural.

Na Figura 5 estão espacializados os valores médios anuais referentes ao número de meses secos, excedente hídrico e déficit hídrico do Alto Vale da Sub-bacia do rio Piracuruca, de 1985 a 2016. Observa-se a preponderância de três a quatro meses secos, distribuídos por $48,3 \%$ (1.202,8 km2) da área pesquisada, excedente hídrico da ordem de 433 a $733 \mathrm{~mm}$, que ocorre em 79,0\% (2.294,4 km2) da área do Alto Vale, déficit hídrico de 106 a $306 \mathrm{~mm}$, identificado em 68,7\% (1.995,3 km2) da área estudada. 


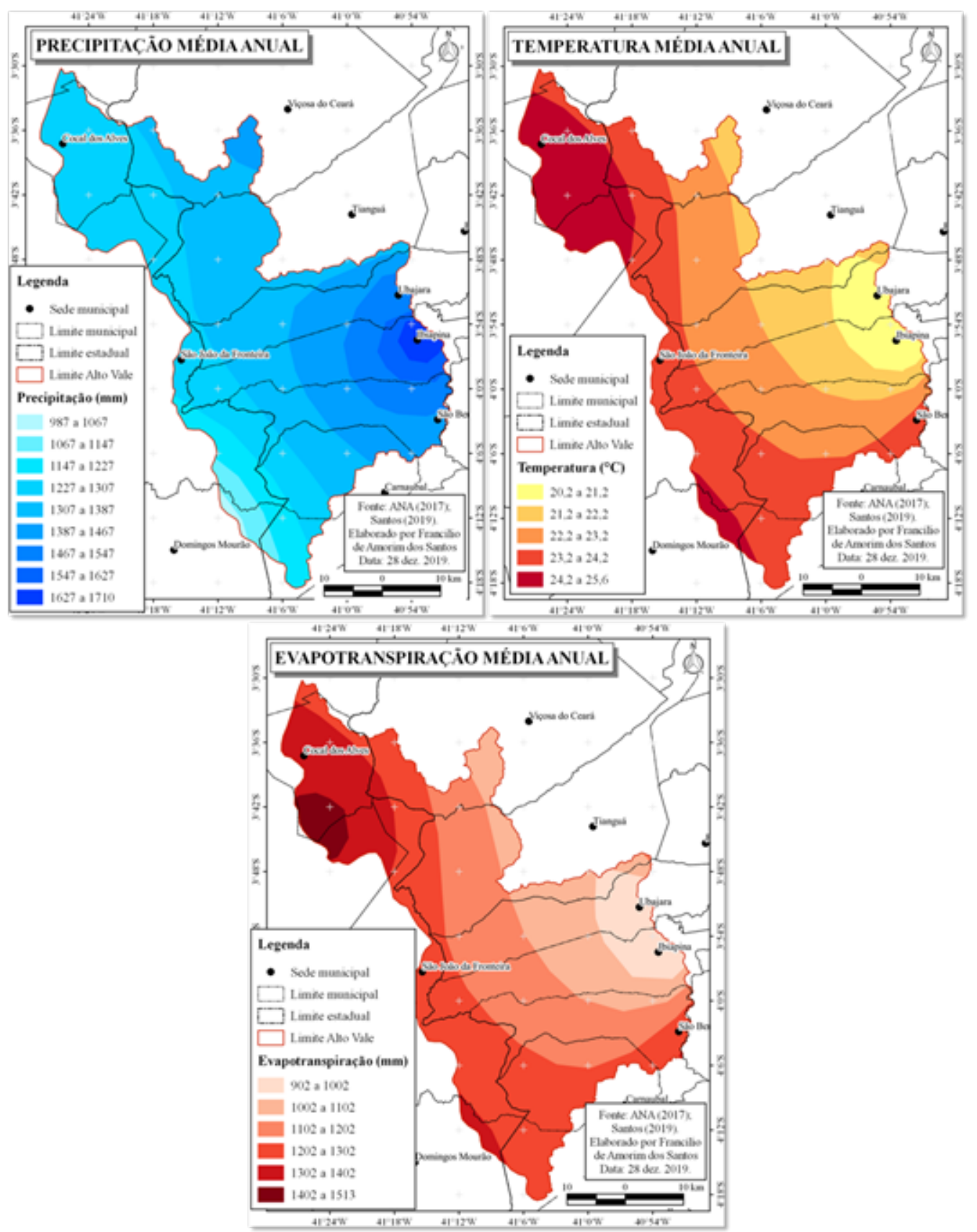

Fonte: Elaborado pelos autores (2019) 
Figura 5 - Médias anuais do número de meses secos, excedente hídrico e déficit hídrico do Alto Vale da Sub-bacia do rio Piracuruca, para o período de 1985 a 2016.

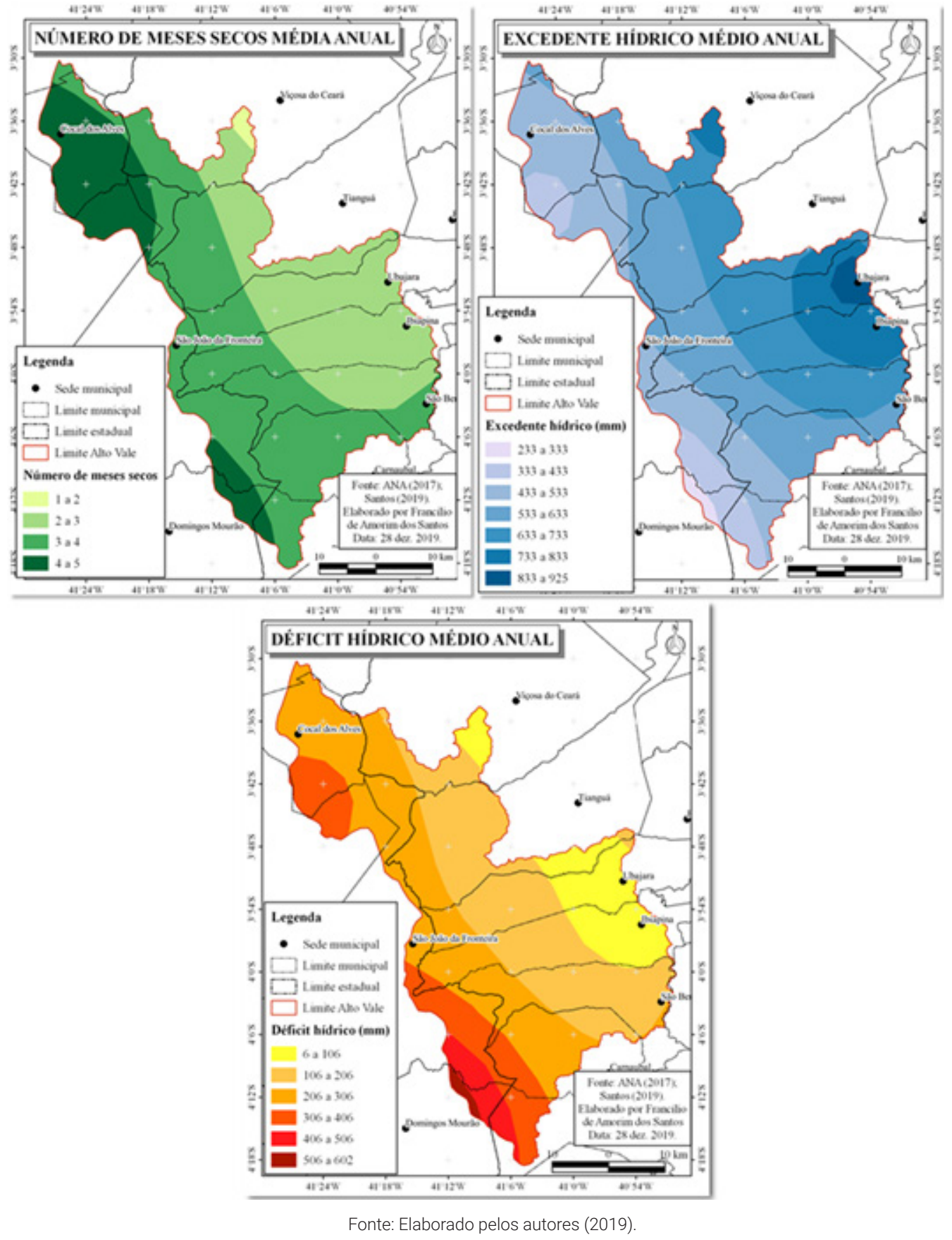

Reitera-se que o número de meses secos aumenta do topo do Planalto em direção ao território piauiense, chegando a 5 meses secos. 0 mesmo ocorre com o excedente e o déficit hídrico, tendo em vista que no topo tem-se o mais elevado volume de excedente e o menor déficit hídrico, onde se destacam as sedes dos municípios de Ibiapina e Ubajara. Aquino e Oliveira (2013) apontam que, para além da disponibilidade de água, a concentração de temporal de chuvas no Nordeste, também, é um problema.

No que concerne ao mosaico de solos presente no Alto Vale, foram identificadas quatro ordens e cinco subordens (INDE, 2014), a saber: os Gleissolos, subordem Melânico, distribuídos por 1,4\% (40,7 km2), estando localizados no topo do Planalto, em áreas de inundação sazonal; os Latossolos, subordem Amarela, que ocupam 22,8\% (662,2 km2) da área pesquisada, típicos de áreas planas, situados no platô do Planalto; por sua vez, os Neossolos, subordem Litólico e Quartzarênico, distribuem-se por 28,2\% (819,0 km2) e $38,5 \%$ (1.118,2 km2), respectivamente, e são encontrados principalmente nas bordas do Planalto; os Planossolos, subordem Háplico, tem ocorrência em 9,1\% (264,3km2) do Alto Vale e foram identificados nas planícies fluviais, situadas do platô às bordas e áreas mais rebaixadas do Planalto da Ibiapaba (Figura 6). 


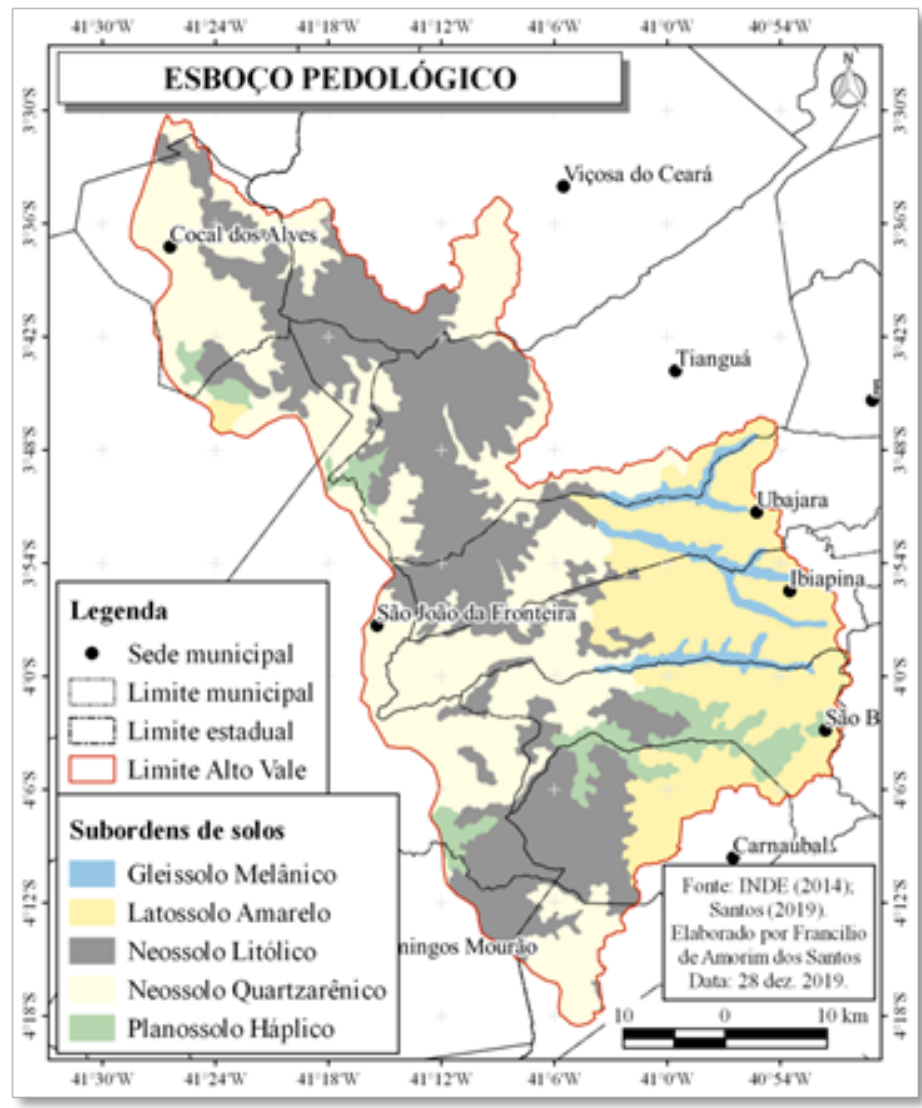

Fonte: INDE (2014)

É preciso perceber que $66,7 \%$ das subordens de solos - Neossolos Litólico e Quartzarênico - do Alto Vale da Sub-Bacia do rio Piracuruca são solos jovens, rasos, pouco desenvolvidos e mal drenados, limitando o armazenamento de água, acentuando o ressecamento dos solos e impactando o crescimento das plantas. Silva, Pinheiro e Chaves (2020) reiteram que, em geral, os solos do Nordeste do Brasil são rasos, pedregosos, praticamente impermeáveis, salinos, arenosos, pobres para agricultura e pecuária e tais características tem grande impacto na qualidade de vida das populações que habitam essa região.

Ressalta-se que a integração das condições ambientais, supracitadas, resultou em um ambiente que possibilitou o desenvolvimento de uma cobertura vegetação diversificada, com uma vegetação de grande porte (mata plúvio-nebular), no topo do Planalto, e caatinga que varia de arbustiva a arbórea, nas bordas do Planalto e áreas mais rebaixadas (SANTOS, 2019).

\section{Indicadores biofísicos}

As variáveis ambientais possibilitaram 0 conhecimento da paisagem do Alto Curso da Sub-bacia do rio Piracuruca, ao passo que a integração das quatro variáveis selecionadas - declividade média do relevo, índice de aridez, temperatura à superfície do solo e índice de vegetação ajustado ao solo - permitiram estimar a suscetibilidade da área estudada à ocorrência de secas. Desse modo, abaixo serão apresentados e discutidos os resultados encontrados para essas quatro variáveis.

\section{Declividade média do relevo (Dm)}

A área apresenta declividade do relevo com cota mínima de $0 \%$, média de $7,0 \%$ e máxima de $74,3 \%$. Na Figura 7 observa-se o predomínio da classe plana, que ocorre por $69,4 \%(2.016,1 \mathrm{~km} 2)$ da área do Alto Curso, e da classe suave ondulada, que se distribui por $19,5 \%$ $(565,9 \mathrm{~km} 2)$ da área pesquisada, que ocorrem por todo o trecho estudado. Por sua vez, a classe ondulada foi identificada em $8,0 \%(232,7 \mathrm{~km} 2)$ do trecho pesquisado e está situada, principalmente, na vertente e parte leste. Por seu turno, as classes forte ondulada e montanhosa compreendem juntas $3,1 \%(89,7 \mathrm{~km} 2)$ do Alto Vale e estão dispersas, particularmente, pelas bordas do Planalto da Ibiapaba. 


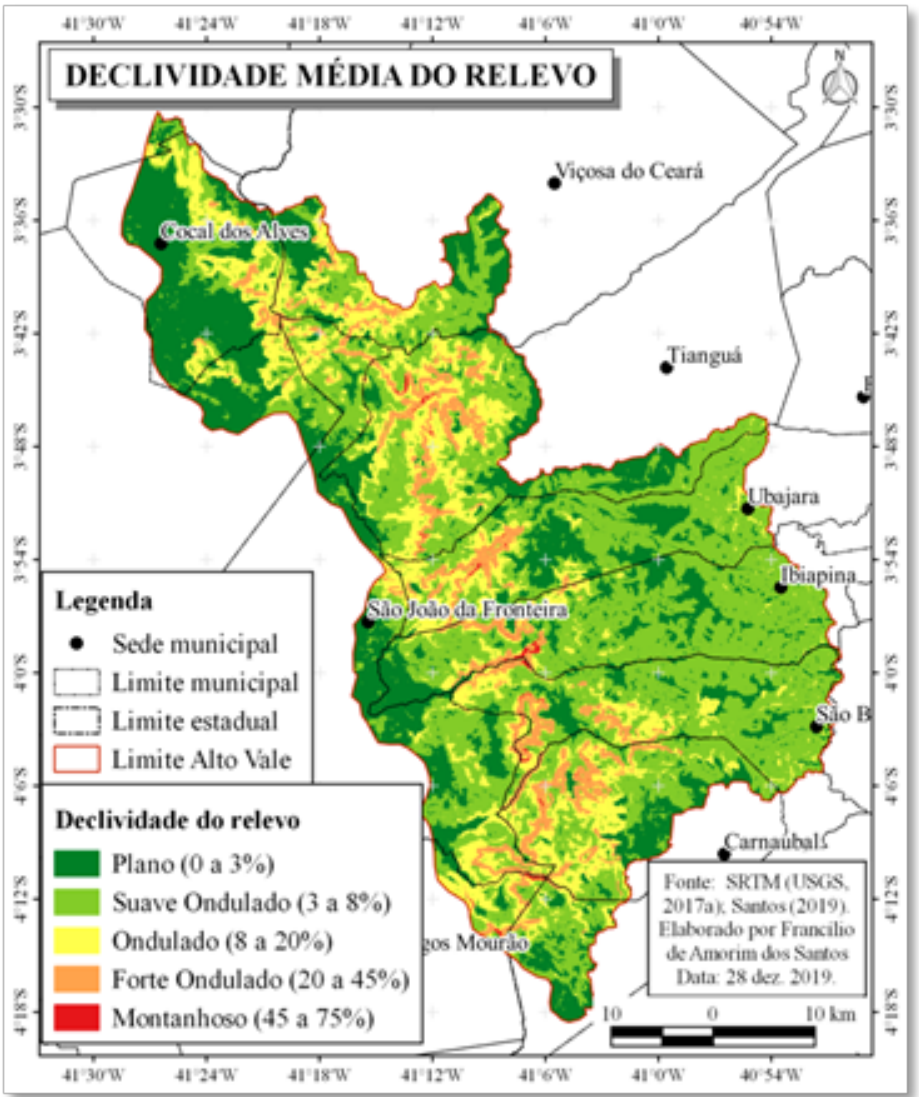

Fonte: Elaborado pelos autores (2019)

Deve-se observar que as áreas de maior inclinação são aquelas, também, com vegetação esparsada e/ ou solo exposto, além de solos rasos e mal drenados, fato que limita o potencial da área para acúmulo de água provinda das concentradas chuvas. Desse modo, essas demonstram ser as áreas mais impactadas pela ocorrência das secas, particularmente na transição do platô do Planalto para as vertentes e, como tal, configuram-se como as mais suscetíveis à ocorrência de secas.

\section{Índice de aridez (la)}

Cabe reiterar a relevância do Planalto da Ibiapaba no condicionamento dos aspectos climáticos do Alto Vale, particularmente das condições de umidade, ou seja, quanto mais próximo ao topo do Planalto menor o rigor climático. Desse modo, observam-se na Figura 8 que as classes de mais baixa aridez estão situadas no platô do Planalto, mais especificamente as classes de aridez muito baixa e baixa, que ocorrem em $15 \%(435,6 \mathrm{~km} 2)$ da área estudada. Por sua vez, as classes de alta e muito alta aridez ocupam juntas $51,8 \%(1.504,5 \mathrm{~km} 2)$ do Alto Vale, com ocorrência principalmente nas vertentes do Planalto. A classe média, segunda mais representativa da área, está presente em 33,2\% (964,3 km2) do Alto Vale e localiza-se em área intermediaria, ou seja, entre o platô e a borda do Planalto. 


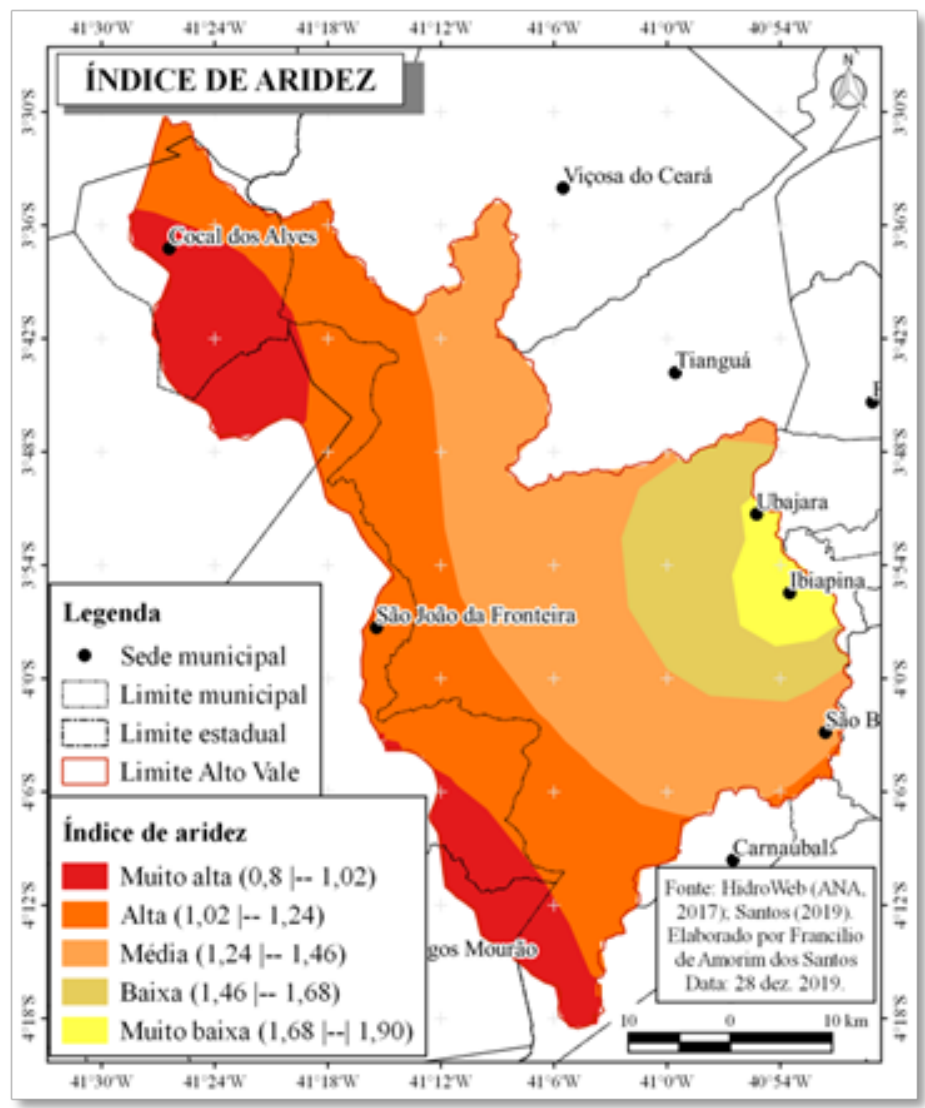

Fonte: Elaborado pelos autores (2019).

Reitera-se que devido aos maiores de volumes pluviométricos e menores perdas por evapotranspiração potencial estarem concentrados no platô do Planalto da Ibiapaba essa área exibe o menor rigor climático, no que diz respeito ao índice de aridez. Ao passo que, o distanciamento em relação ao platô resulta em aumento do nível de aridez, fruto da redução do volume de chuvas e maior perda de água por evapotranspiração.

Cabe destacar os resultados do estudo de Santos et al. (2010), que simulou dois cenários para o índice de aridez médio (lamed) considerando o Nordeste do Brasil, apontando que em $64 \%$ das estações analisadas ocorreu o maior aumento do lamed entre a situação atual (2007) e o cenário para o ano de 2050 , ao passo que em $28 \%$ das estações o maior aumento ocorreu entre os cenários de 2050 e 2100.

Temperatura à superfície do solo (Ts)

A variável temperatura à superfície do solo vem corroborar os valores encontrados no índice de aridez, ou seja, a interferência do Planalto no condicionamento de umidade na área estudada, cujas temperaturas médias mais baixas ocorrem no platô do Planalto, como se pode observar na Figura 9. Contudo, predominam na área as temperaturas situadas entre 30,1 a $36,0^{\circ} \mathrm{C}$, frequentes em $80,2 \%$ (2.329,3 km2), particularmente na vertente do Planalto da Ibiapaba. Segue-se a essa classe a de 26,1 a $30,0^{\circ} \mathrm{C}$, cuja ocorrência dá-se em $16,9 \%(490,8 \mathrm{~km} 2)$ do Alto Vale e situa-se, principalmente, na parte centroleste do trecho estudado. Por sua vez, as temperaturas compreendidas nos intervalos 21,1 a $26,0^{\circ} \mathrm{C}$ e 36,1 a $40,0^{\circ} \mathrm{C}$ ocorrem, respectivamente, em 1,9\% (55,2 km2 / platô do Planalto) e 1,0\% (29,0 km2 / vertente do Planalto) do Alto Vale.

Observa-se que, assim como os demais elementos do clima, a temperatura à superfície do solo, também, apresenta influência do Planalto da Ibiapaba, ou seja, o afastamento em direção ao estado do Piauí tende a ter aumento na temperatura. Tal fato é fruto do aquecimento/ 
resfriamento adiabático que ocorre no lado Leste do Planalto (vertente barlavento), que concentra o maior nível de umidade, em detrimento da vertente sotavento (Oeste), que fica mais seca e quente.

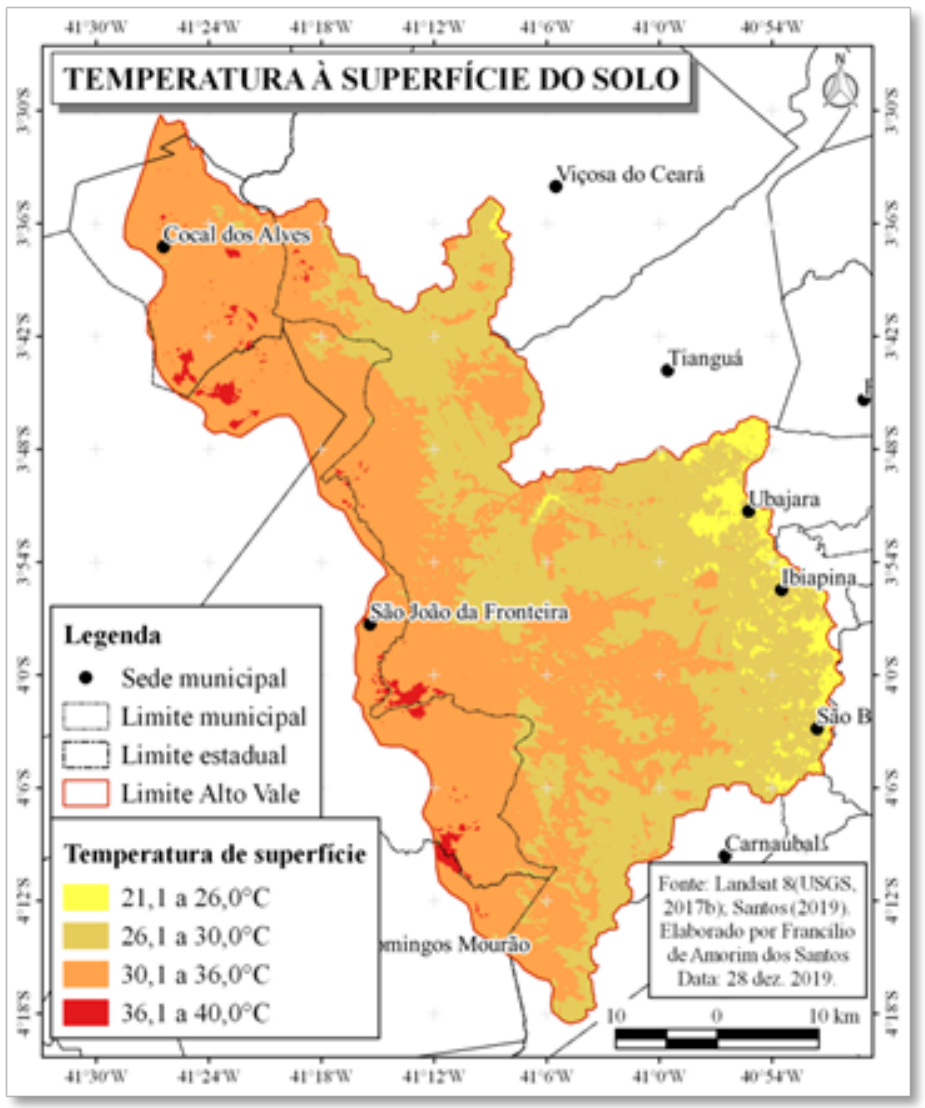

Fonte: Elaborado pelos autores (2019)

\section{Índice de vegetação ajustado ao solo (SAVI)}

Ressalta-se que o Alto Vale é o setor da Sub-bacia do rio Piracuruca que apresenta a cobertura vegetal de maior porte (Figura 10). Desse modo, destaca-se que no Alto Vale encontram-se corpos hídricos, com destaque para o açude Jaburu I, e solo exposto na ordem de $0,1 \%$ $(3,9 \mathrm{~km} 2)$ e $0,1 \%(1,7 \mathrm{~km} 2)$, respectivamente. Ao passo que a classe mais expressiva na área é de vegetação com baixa atividade fotossintética, que se distribui por
$62,0 \%(1.800,4 \mathrm{~km} 2)$, ocorrendo praticamente por toda a área pesquisada. Na sequência aparece a classe de média atividade fotossintética, que se dispersa por $24,3 \%$ $(637,1$ km2) e está localizada, principalmente, no platô do Planalto. Por sua vez, as classes área urbana / muito baixa atividade fotossintética (transição do platô para as vertentes do Planalto) e alta atividade fotossintética (platô do Planalto) foram identificadas em 13,4\% (390,4 km2) e 2,4\% (70,9 km2), respectivamente. 


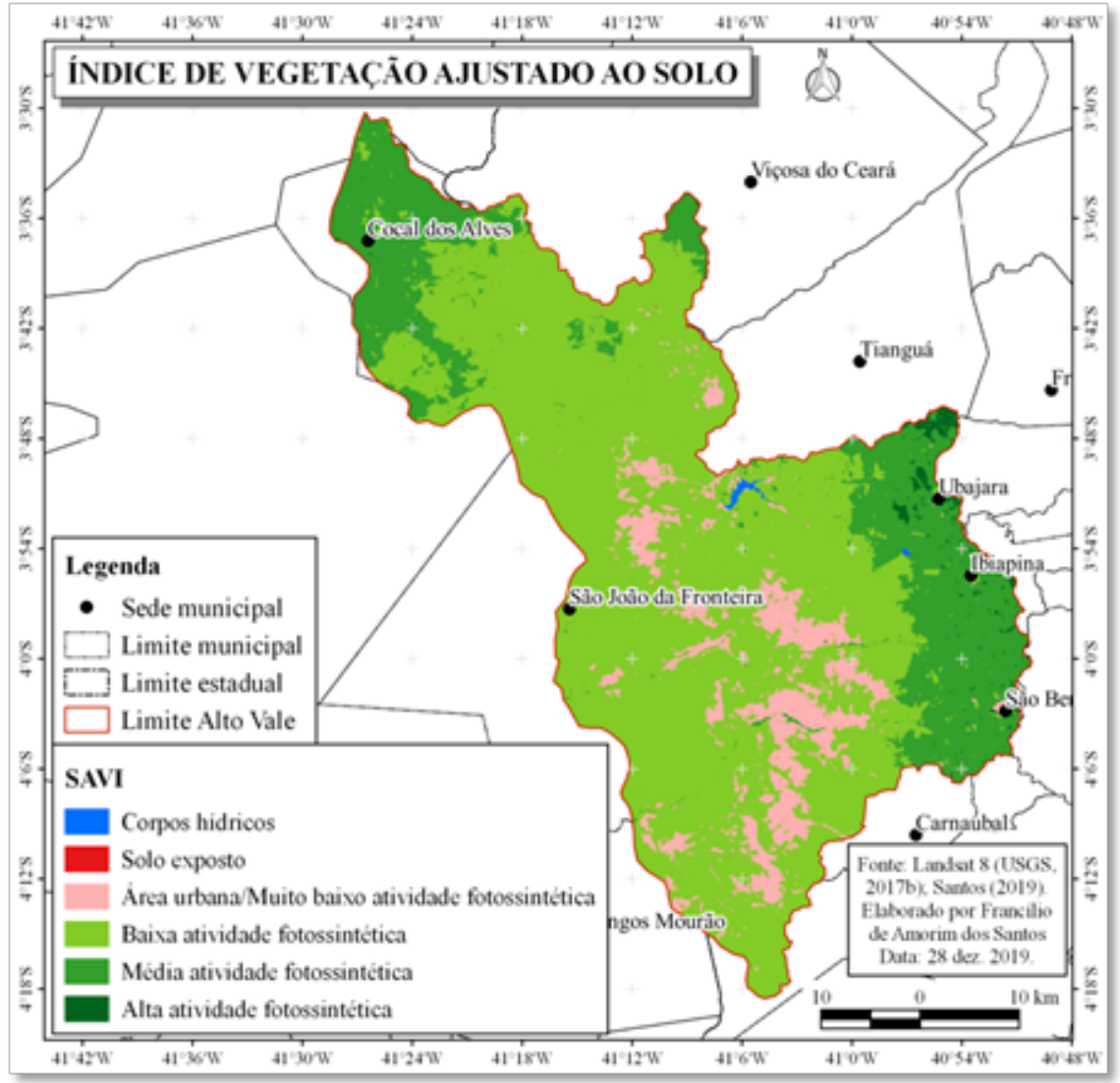

Fonte: Elaborado pelos autores (2019)

A vegetação como elemento da paisagem, cuja fisionomia é fruto da integração de distintas condições físicas, apresenta-se diversificada na área estudada. Desse modo, o platô por possuir áreas planas, solos mais profundos e maiores volumes pluviométricos exibe vegetação de maior porte, com alta atividade fotossintética. Ao passo que em direção do estado do Piauí, a declividade vai aumentando, os solos ficando mais rasos e os níveis de precipitação reduzindo, de tal modo que a vegetação vai, também, reduzindo sua fisionomia. Tal fato tem impacto direto nas condições de seca na área, pois a vegetação permite uma maior retenção de água e atenuação da temperatura local.

\section{Índice de suscetibilidade biofísica a secas (ISBioS)}

Quando integrados os produtos das quatro variáveis discutidas, acima, foi possível estimar a suscetibilidade biofísica a secas do Alto Vale da Sub-bacia do rio Piracuruca, conforme se pode observar na Figura 11. Desse modo, foi identificado que a classe alta de suscetibilidade a secas predomina na área estudada, ocorrendo por $35,3 \%(1.025,3 \mathrm{~km} 2)$ da área pesquisada, principalmente na vertente do Planalto da Ibiapaba. Por sua vez, a classe média, segunda mais representativa, distribui-se por $34,6 \%(1.004,9 \mathrm{~km} 2)$ do Alto Vale, particularmente, na área de transição entre o platô e a vertente do Planalto. Por sua vez, a classe muito baixa e a classe baixa estão localizadas no platô do Planalto e somam $22,6 \%(656,4 \mathrm{~km} 2)$, enquanto a classe muito alta que foi identificada em 7,5\% (217,8 km2), localizada pontualmente, principalmente, no setor Sul da área. 


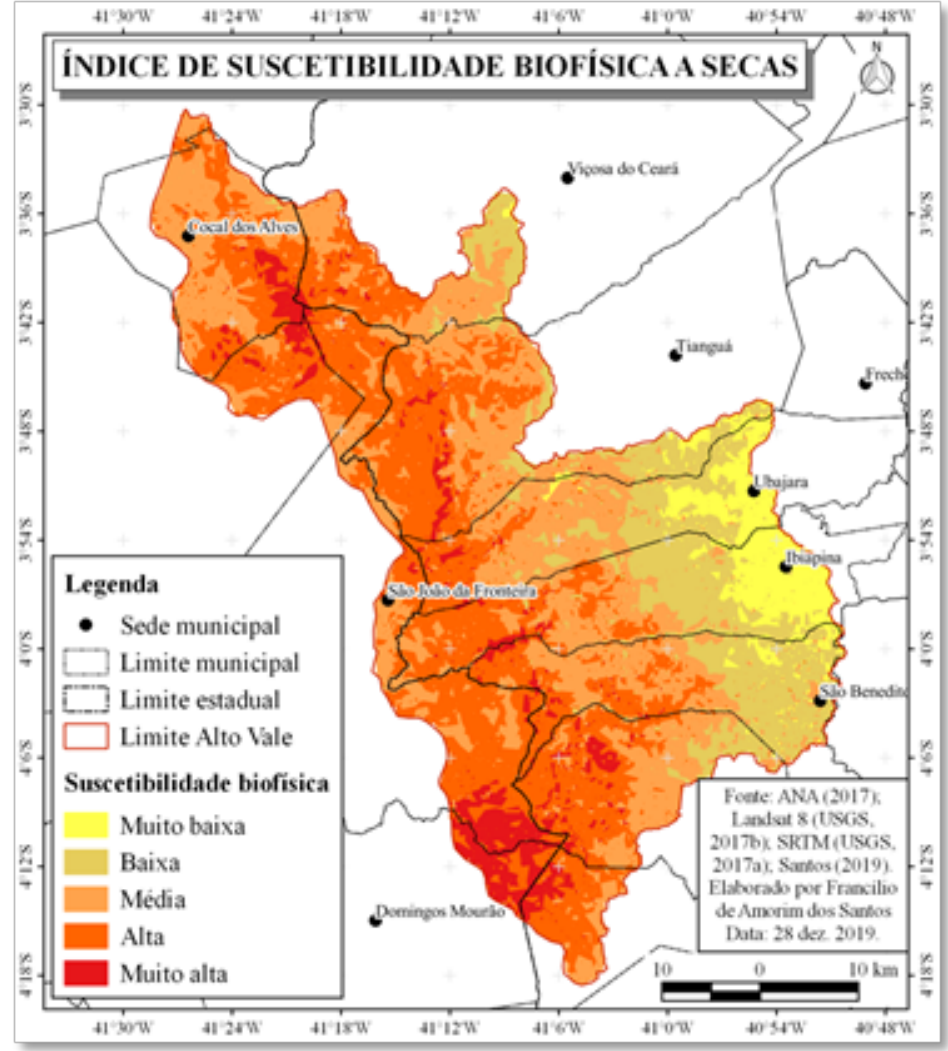

Fonte: Elaborado pelos autores (2019)

Os valores encontrados para a suscetibilidade a secas, particularmente da classe alta e classe muito alta, tem influência direta dos níveis de aridez, da temperatura à superfície do solo, da cobertura vegetal com baixa atividade fotossintética e do relevo forte ondulado e montanhoso, que se concentram na vertente Oeste do Planalto da Ibiapaba. Deve-se destacar a influência dessa estrutura geomorfológica no condicionamento de umidade do trecho estudado, que associado aos demais elementos da paisagem produzem um ambiente de alta suscetibilidade à ocorrência de secas.

\section{Conclusões}

Destaca-se a importância da metodologia aplicada, tendo em vista que possibilitou alcançar o objetivo proposto. Desse modo, pode-se identificar que no Alto Vale predomina: relevo com declividade plana, que ocorre em $69,4 \%$; aridez alta e muito alta que somam $51,8 \%$; temperatura à superfície do solo situada entre 30,1 a $36,0^{\circ} \mathrm{C}$, que se distribui por $80,2 \%$; classe de vegetação com baixa atividade fotossintética, que se dispersa por distribui por $62,0 \%$.

Por sua vez, a álgebra de mapas possibilitou estimar a suscetibilidade biofísica às secas na área estudada, onde se constatou que em $35,3 \%$ do Alto vale prevalece a classe alta de suscetibilidade a secas, que se localiza principalmente na vertente do Planalto da Ibiapaba. Tal conclusão reafirma a influência que o Planalto da Ibiapaba exibe sobre o condicionamento de umidade na área estudada.

Diante do exposto, devem-se tomar as informações apresentadas como ponto de partida para planejamento e (re)orientação da ocupação da área do Alto Vale, bem como produção de plano de manejo e/ou estratégias para conservação e uso condizente com a capacidade de suporte do ambiente. Destaca-se, ainda, a necessidade de conhecimento das condições socioeconômicas da população residente como forma de compreender a sua vulnerabilidade à ocorrência de desastres naturais, particularmente as secas. 


\section{Referências}

ARTIS, D.A.; CARNAHAN, W.H. Survey of Emissivity Variability in Thennography of Urban Areas. Remote Sensing of Environment, v.12, p.313-329, 1982.

AQUINO, C.M.S.; OLIVEIRA, J.G.B. Emprego do Método de Thornthwaite \& Mather (1955) para Cálculo do Balanço Hídrico Climatológico do Núcleo de Degradação de São Raimundo Nonato-Piauí. Revista Brasileira de Geografia Física, Recife, v. 6, n. 1, p. 79-90, 2013.

AYOADE, J.O. Introdução à climatologia para os tópicos. Tradução de Maria Juraci Zani dos Santos; revisão de Suely Bastos; coordenação editorial de Antonio Christofoletti. 6. ed. Rio de Janeiro: Bertrand Brasil, 2001. 332p.

BORATTO, I.M.P.; GOMIDE, R.L. Aplicação dos índices de vegetação NDVI, SAVI e IAF na caracterização da cobertura vegetativa da região Norte de Minas Gerais. In: SIMPÓSIO BRASILEIRO DE SENSORIAMENTO REMOTO, 16., 2013, Foz do Iguaçu, Anais... Foz do Iguaçu: SBSR, 2013, p.7.345-7.352.

BRASIL. Ministério da Integração Nacional. Política Nacional de Defesa Civil. Brasília: 2007.

CENTER FOR RESEARCH ON THE EPIDEMIOLOGY OF DISASTERS. EMERGENCY EVENTS DATABASE. Explanatory Notes: Classification. Université Catholique de Louvain (UCL), Bruxelas. Disponível em: <http://www.emdat.be/classification>. Acesso em: 15 fev. 2017.

GIL, A.C. Como elaborar projetos de pesquisa. 4. ed. São Paulo: Atlas, 2002.

INFRAESTRUTURA NACIONAL DE DADOS ESPECIAIS. Mapa de Solos da Folha SB.24 - Jaguaribe. Disponível em: <http:// www.visualizador.inde.gov.br/>. 2014. Acesso em: 13 set. 2018.

INSTITUTO BRASILEIRO DE GEOGRAFIA E ESTATÍSTICA. Agregados por setores censitários dos resultados de universo. Censo 2010a. Disponível em: <https://www.ibge.gov.br/estatisticas/sociais/populacao/9662-censo-demografico-2010. html?edicao=10410\&t=resultados>. Acesso em: 25 jun. 2018.

Índice de recortes para fins estatísticos: malha de setores censitários, censo 2010, base de faces de logradouros para o CE. Censo 2010b. Disponível em: <ftp://geoftp.ibge.gov.br/recortes_para_fins_estatisticos/malha_de_setores_ censitarios/censo_2010/base_de_faces_de_logradouros/CE>. Acesso em: 25 jun. 2018.

Manual Técnico de Geomorfologia. Coordenação de Recursos Naturais e Estudos Ambientais. 2. ed. Rio de Janeiro: IBGE, 2009.

LIMA, M.G.; ALENCAR, P.A.M.; COELHO, H. Normais de temperatura máxima, mínima e média estimadas em função da latitude, longitude e altitude para o estado do Piauí. Ensaios: Boletim de Pesquisa, v. 1, n. 1, p.1-40, 1982.

LISTO, F.L.R. Análise da suscetibilidade e do grau de risco a escorregamentos rasos na Bacia do Alto Aricanduva, RMSP (SP). 2011. 151f. Dissertação (Mestrado em Geografia) - Universidade de São Paulo. São Paulo, 2011.

NATIONAL AERONAUTICS AND SPACE ADMINISTRATION. Landsat Science. Disponível em: <https://landsat.gsfc.nasa. gov/landsat-8/landsat-8-bands/>. Acesso em: 23 jan. 2019.

PENMAN, H.L. The Physical Bases of Irrigation Control, in Report 13th Int. Hort. Congr., 2, 11 pages, Royal Horticultural Society, London, 1953.

PINHEIRO, R.A.B. Análise do processo de degradação/desertificação na bacia do Riacho Feiticeiro, com base no DFC, município de Jaguaribe-Ceará. 129f. Dissertação (Mestrado em Desenvolvimento e Meio Ambiente) - Universidade Federal do Ceará. Fortaleza, 2011.

OLIVEIRA, J.G.B.; SALES, M.C.L. Usuais: programas para uso em análise ambiental. Revista Equador (UFPI), Teresina, PI, vol.5, n.2, p.36-60, Janeiro/Junho, 2016.

RAMOS, V.M. Indicadores do tipo ambiental em situações de seca. 2010. 239f. Dissertação (Mestrado em Engenharia do Ambiente) - Universidade do Porto. Porto, 2010.

RÊGO, R.L.M; CATÃO, W.V.C.; CHAVES, T.L.D.; CRUZ, P.S.C; BARROS, A.P.R. Impactos da seca: histórico, causas e consequências. In: Congresso Internacional da Diversidade do Semiárido, 1., 2018, Campina Grande. Anais... Campina Grande: Editora Realize, 2018, p.1-11.

SANTOS, D.N; SILVA, V.P.R.; SOUSA, F.A.S.; SILVA, R.A. Estudo de alguns cenários climáticos para o Nordeste do Brasil. Revista Brasileira de Engenharia Agrícola e Ambiental, Campina Grande, v.14, n.5, p.492-500, 2010.

SANTOS, F.A. Resiliência ambiental a secas e a inundações na Sub-bacia Hidrográfica do rio Piracuruca (CE-PI). 268p. Tese (Doutorado em Geografia) - Universidade Estadual do Ceará. Fortaleza, 2019.

SERVIÇO GEOLÓGICO DO BRASIL. Ministério de Minas e Energia. Mapa Geológico do Estado do Piauí. 2a Versão. Teresina, 2006a.

Mapas estaduais de geodiversidade: Ceará. Rio de Janeiro: CPRM. 2006b. Documento cartográfico em arquivo 
vetorial. Disponível em <http://geobank.sa.cprm.gov.br>. Acesso em: 14 jan. 2014.

SILVA, G.V.L.; PINHEIRO, L.F.; CHAVES, B.E. Seca no Nordeste: o mau aproveitamento e uso errado do solo. 0 Estado. Fortaleza, terça-feira, 17 out. 2017. Disponível em: https://www.oestadoce.com.br/cadernos/oev/seca-no-nordeste-omau-aproveitamento-e-uso-errado-do-solo/. Acesso em: 08 jul. 2020.

SUERTEGARAY, D.M.A. Geografia física e geomorfologia: tema para debate. Revista da ANPEGE, Dourados, v.5, n.1, p.1726, 2009.

THORNTHWAITE, C.W. An approach toward a rational Classification of Climate, The Geographical Review. New York, v.XXXVIII, p.55-94, 1948.

Atlas of Climatic Types in the United States. Miscell Publ. n.421. U.S. Departament of Agricultures, Forest

Service, 1941

TUCCI, C.E.M. Hidrologia: ciência e aplicação. Porto Alegre: Eds. da UFRGS e da USP, 1993.

UNITED NATIONS ENVIRONMENT PROGRAMME. Status of desertification and implementation of the United Nations Plan of Action to Combat Desertification. Nairóbi, 1991.

UNITED STATES GEOLOGICAL SERVICE (Serviço Geológico dos Estados Unidos). Digital elevation: SRTM 1 Arc-Second Global. 2017. Disponível em: <http://earthexplorer.usgs.gov/>. Acesso em: 23 nov. $2017 a$.

Collection: landsat archive. Disponível em: <http://earthexplorer.usgs.gov/>. Acesso em: 23 nov. 2017b.

VALOR, E.; CASELLES, V. Mapping Land Surface Emissivity from NDVI: Application to European, African, and South American Areas. Remote Sensing of Environment, v.57, p.167-184, 1996.

ZHANG, X.; LIAO, C.; LI, J.; SUN, Q. Fractional vegetation cover estimation in arid and semi-arid environments using HJ-1 satellite hyperspectral data. Int. J. Appl. Earth Observ. Geoinf., p.1-7, 2012. 